\title{
A RELAÇÃO ENTRE UNIVERSIDADE E MOVIMENTOS SOCIAIS COMO PRINCÍPIO DA CONSTRUÇÃO CRÍTICA DA EDUCAÇÃO DO CAMPO ${ }^{1}$
}

\section{THE RELATIONSHIP BETWEEN UNIVERSITY AND SOCIAL MOVEMENTS AS A PRINCIPLE IN THE CRITICAL CONSTRUCTION OF RURAL EDUCATION}

\author{
Maria da Glória Gohn* \\ Yolanda Zancanella*
}

\begin{abstract}
Resumo: O artigo apresenta resultados de pesquisa realizada com egressos e graduandos do Curso de Pedagogia para Educadores do Campo da Universidade Estadual do Oeste do Paraná (Unioeste), campi de Francisco Beltrão e Cascavel, com o objetivo de analisar "O que move o MST na busca do ensino superior para os seus militantes?”. Aborda a relação entre universidade e movimentos sociais, analisando a formação superior universitária dos militantes do Movimento dos Trabalhadores Rurais Sem Terra (MST). Discutem-se o direito da população do campo ao acesso ao Ensino Superior, a responsabilidade da universidade e seu compromisso com a sociedade civil, e o papel do Estado na garantia dos direitos fundamentais dos indivíduos e grupos. Os resultados evidenciam que as ações dos movimentos sociais refletem-se nas suas conquistas no âmbito social, político e cultural, e que a formação superior universitária é concebida como uma perspectiva fundamental na luta dos militantes do MST, sob o ponto de vista do acesso ao conhecimento prático-teórico aplicável no trabalho, objetivo que inclui a formação política de sua base.
\end{abstract}

Palavras-chave: Ensino Superior universitário. Movimento dos Trabalhadores Rurais Sem Terra. Educação do campo. Universidade. Pedagogia.

Abstract: This article presents results from a research carried out by former students and undergraduate students from the Pedagogy Course for Rural Educators of the State University of the West of Paraná (Unioeste), from the Francisco Beltrão and Cascavel campuses with the aim of answering the question "Why does the Landless Workers Movement looks for Higher Education for its militants? " The article discusses the relationship between the university and social movements and analyzes the higher education of the militants of the Landless Rural Workers Movement (MST Portuguese acronym). The article also discusses the right to higher education of rural populations, the responsibility of the university and its commitment with civil society, the role of the state to guarantee the fundamental rights of individuals and groups. The results demonstrate that the actions of the social movements reflect in their social, political and cultural accomplishments, and that the higher education is conceived as a fundamental

${ }^{1}$ O presente trabalho foi realizado com o apoio da Fundação Araucária/SETI - PR, por meio de bolsa concedida a Yolanda Zancanella. This study was carried out with the support of Fundação Araucária/SETI -PR, with a grant awarded to Yolanda Zancanella.

* Professora da Universidade Estadual de Campinas. Pós-Doutora pela New School university/N.York/USA. E-mail: <mgohn@uol.com.br>.

* Post-Doctoral at the New School University/N.York/USA - Institution: State University of Campinas - São Paulo/ SP. E-mail: <mgohn@uol.com.br>.

** Professora da Universidade Estadual do Oeste do Paraná. Doutora em Educação pela Universidade Estadual de Campinas. E-mail: <yolandazanca@yahoo.co>.

${ }^{* *}$ Doctor in Education from the State University of Campinas, Unicamp-Campinas/SP-Institution-State University of the West of Paraná - Unioeste - PR. E-mail: <yolandazanca@yahoo.com.br> 
perspective to the MST's militants as it gives access to practical-theoretical knowledge that can be applied to work, a goal that includes the political formation of its base.

Keywords: Higher Education. Landless Rural Workers Movement. Rural Education. University. Pedagogy.

\section{Introdução}

Aliada à pressão pela democratização, a crise econômica e política que figurou nas décadas de 1970 e 1980 trouxe para o cenário político os antigos e os novos personagens, a exemplo de movimentos sociais, partidos políticos, artistas, intelectuais e demais atores públicos. Com eles, o país se deparou mais uma vez com demandas econômicas, políticas, culturais e sociais, enfatizando a luta pela educação que fora minimizada no período ditatorial, com reedição da bandeira da educação pública para todos gratuita e com qualidade, conforme SADER (2001). Nesse embate, as forças sociais foram compostas por professores e funcionários no enfrentamento com o Estado, quanto aos projetos autoritários para o ensino, a pesquisa e a extensão universitária.

As décadas de 1980 e 1990, por sua vez, registram na educação universitária brasileira a criação de vínculos importantes com questões sociais de classes excluídas do processo, caracterizados pela Universidade do Trabalhador, Universidade Popular, Universidade dos Movimentos Sociais e por medidas que o Programa Universidade para Todos (ProUni) - o sistema de reserva de vagas para estudantes negros, indígenas e alunos que procedem da rede pública de ensino básico - compreende.

Gohn (2008a), referindo-se ao protagonismo dos movimentos sociais no Brasil, mostra que, na década de 1990, ganhava força um sujeito sociopolítico, o Movimento dos Trabalhadores Rurais Sem Terra (MST), ao rearticular o seu papel na sociedade. Da sociedade civil, por meio dos movimentos sociais, são criadas as reivindicações que o Estado deve acolher mediante criação de políticas públicas ou programas que atendam a demanda, sobretudo, da formação universitária da população do campo.

Analisando esse protagonismo, verificam-se resultados significativos: mesmo que as políticas elitizantes continuassem a ser implementadas na universidade, as ações dos movimentos sociais repercutiram em experiências de lutas nesse espaço social. Em conjunto com a rearticulação de uma frente de luta ligada ao processo de reconfiguração das lutas sociais por terra e reforma agrária no campo, o MST buscou o acesso à Educação Superior universitária, requerendo aumento de vagas e democratização na entrada e na permanência.

\section{Os movimentos sociais e a luta pelo direito ao acesso ao Ensino Superior universitário}

Com suas variações políticas e ideológicas, o Estado tem mantido a educação nos moldes do sistema tradicional, que privilegia as classes sociais mais abastadas em detrimento do acolhimento de indivíduos mais fragilizados socialmente. Estes estão distanciados dos recursos da educação como diferencial para argumentações e discussões concernentes aos direitos sociais como um 
todo, ou seja, cala-se a voz dos oprimidos pela omissão, pela ignorância e pela limitação de acesso aos seus direitos sociais.

O surgimento da luta promovida pelos movimentos sociais, em específico o MST, em prol de uma educação que contemple as especificidades da população do campo e que permita o acesso de seus integrantes ao ensino superior universitário já é história presente na educação nacional. Na atualidade, parte-se para outros desafios, de contornos mais aguerridos e de comprometimento coletivo.

O movimento da educação do campo levantou e expôs ao Estado os diferentes problemas vividos pela população do campo, presentes desde a iniciação na escola até a formação superior universitária. Diante das várias situações que constituem esses problemas - como a falta de escolas do campo; a crescente nucleação ${ }^{2}$, que afirma a precariedade daquelas escolas que ainda se mantêm e que, aos poucos, são fechadas; o insuficiente número de professores e a carência de qualificação necessária para a docência acrescenta-se a falta de um projeto político-pedagógico voltado ao modelo de vida e de vivência dos sujeitos do campo, com relação à sua realidade.

\footnotetext{
${ }^{2}$ A nuclearização de escolas caracteriza o fechamento de pequenas escolas do campo e o agrupamento das mesmas em uma região rural, criando-se a denominada Escola-Núcleo, uma instituição dotada de características próprias de organização e funcionamento. Essa nuclearização de escolas rurais tem por objetivo concentrar os materiais didáticos e as instalações em um local apenas, de modo a proporcionar ensino de qualidade aos alunos. Não é a nossa intenção neste texto aprofundar as questões sobre a nuclearização. Para saber mais ver OLIVEIRA, Ana Maria Vergne de Morais. A Nucleação de Escolas do Campo como estratégia de melhora do ensino: esboços de compreensão. Disponível em: <www.encontroobservatorio.unb.br/arquivos/artigos/300>. EDSON Bareiro. Políticas educacionais e escolas rurais no Paraná - 1930-2005. Maringá, 2007 - Dissertação de mestrado.
}

A relevância do papel dos movimentos sociais aparece na luta para a construção da educação do campo, quando protagonizam a defesa de uma educação destinada aos sujeitos que mantêm consigo valores, costumes, identidade e cultura singulares. Os resultados e ações dos movimentos sociais são sentidos nas conquistas que se efetivam no âmbito social, político e cultural, a exemplo do aumento no número de oferta de curso superior universitário para educadores do campo.

Ao longo das lutas e sob o aspecto democrático que o Brasil constitucional determina, o MST adquire a legitimidade enquanto movimento negociador junto ao Estado, como representante da população do campo. O fortalecimento da ideia de um modelo novo para o desenvolvimento rural encontra-se vinculado às demais transformações vividas pelo país. O destaque para o MST, nessa caminhada, vai além do aspecto massivo de luta; está, sobretudo, na apresentação de projetos sociais que busquem recursos públicos para o desenvolvimento da educação (STÉDILE; FERNANDES, 2005).

Dentre as estratégias do MST, encontra-se uma das mais importantes: a ampliação do conhecimento coletivo, por meio da educação; com isso, pretende fortalecer-se como movimento social e, assim, fortalecer também a base dos Sem Terra. Ao lutar pela formação superior universitária de seus integrantes, o MST fundamenta as suas estratégias de atuação.

Com a formação superior universitária de seus integrantes, em nenhum momento se esquece, nas ações e lutas do MST para a educação, da importância que o conhecimento científico institucionalizado tem, somado ao conhecimento histórico que a população do campo domina, para fortalecer as bases do MST e provocar mudanças nas escolas do campo. 
No cenário dos movimentos sociais, um elemento é de incontestável importância: o caráter educativo, especialmente quando suscita questionamentos a respeito do protagonismo nas ações pedagógicas para a formação de um sujeito novo, dissociado do cidadão liberal burguês. Assim, se existe um projeto político-pedagógico como fundamento para essa formação organizativa e política, Gohn já havia registrado que:

Aprende-se a não ter medo de tudo aquilo que foi inculcado como proibido e inacessível. Aprende-se a decodificar o porquê das restrições e proibições. Aprende-se a acreditar no poder da fala e das ideias, quando expressas em lugares e ocasiões adequadas. Aprende-se a calar e a se resignar quando a situação é adversa. Aprende-se a criar códigos específicos para solidificar as mensagens e bandeiras de luta, tais como as músicas e folhetins. Aprende-se a elaborar discursos e práticas segundo os cenários vivenciados. E aprende-se, sobretudo, a não abrir mão de princípios que balizam determinados interesses como seus. Ou seja, elaboram-se estratégias de conformismo e resistência, passividade e rebelião, segundo os agentes com os quais se defronta. (GOHN, 2009, p. 19).

O interesse da sociedade pela Educação Superior universitária tem aumentado significativamente. Na história da educação vivenciada pelo MST, informações revelam dados muito significativos de evolução nas conquistas: há 300 mil trabalhadores e trabalhadoras rurais estudando, entre crianças e adolescentes sem-terra, sendo $120 \mathrm{mil}$ em escolas públicas; mais de 350 mil integrantes do MST já se formaram em cursos de alfabetização, ensino fundamental e médio, ensino superior e cursos técnicos (MST, 2010).

O documento do MST (2010) informa que a formação pelo movimento é de mais de $4 \mathrm{mil}$ professores, e que cerca de $10 \mathrm{mil}$ professores atuam nas escolas em acampamentos e assentamentos, com resultados relevantes de que mais de 100 mil sem-terra foram alfabetizados, entre crianças, jovens e adultos. A média anual é de aproximadamente 28 mil educandos e 2 mil professores envolvidos em processos de alfabetização.

Por meio de parcerias com as universidades públicas, cerca de 5 mil trabalhadores e trabalhadoras rurais do MST estudam em 50 instituições de ensino superior, havendo 100 turmas de cursos formais. São cursos técnicos de nível médio, como Administração de Cooperativas, Saúde Comunitária, Magistério e Agroecologia, e cursos superiores e especializações, os quais compreendem Pedagogia, Letras, Licenciatura em Educação do Campo, Ciências Agrárias, Ciências Sociais, Ciências Naturais, Agronomia, Veterinária, Direito, Geografia e História (MST, 2010).

A constituição da natureza política e social do MST recebe influência direta de diferentes ideologias, determinando-se como um elemento essencial do movimento quanto à formação política de sua base. Tal fato conduz ao provimento da Educação Básica, alfabetização de jovens e adultos, e ao Ensino Superior de seus militantes.

\section{A universidade como instituição social e a relação com os movimentos sociais do campo}

Ao falar sobre a universidade e sua função social, Valença (2009) deixa implícito que se refere à universidade pública, por considerar que todas as pessoas têm direito à educação. Quando trata da inclusão, o autor ressalta que os movimentos sociais e organizações não governamentais também devem fazer parte desse universo inclusivo. 
Segundo Valença (2009), Santos (1997) critica o isolamento da universidade em relação aos problemas da contemporaneidade. Por outro lado, afirma que no momento em que a universidade deixa de ser a procura apenas por excelência e passa a vivenciar, também, a procura da democracia e da igualdade na execução de cursos para sujeitos dos movimentos sociais, ela estará realmente cumprindo o seu papel (VALENÇA, 2009).

Pensar a universidade em seu papel social e nas ações realizadas pelo MST em prol da formação humana, formação e reprodução implica pensar na contribuição que cada indivíduo, em particular, e no coletivo como um todo, pode ter para o conjunto de interesses desse movimento.

Nesse contexto, o MST, sem dúvida, pode ser considerado o movimento social de importância vital para o início do Movimento de Educação do Campo. Ao par de sua permanência, entretanto, convém assinalar que outros sujeitos coletivos forjados em torno da questão do campo, com entrada mais

tarde nesse Movimento, constituem, hoje, essa dinâmica. Destaque-se as organizações de âmbito nacional ou regional, como por exemplo, Movimento dos Atingidos pelas Barragens (MAB), o Movimento das Mulheres Camponesas (MMC), o Movimento dos Pequenos Agricultores (MPA), sindicatos e federações estaduais vinculados à Confederação dos Trabalhadores da Agricultura (CONTAG), assim como "seu" Movimento de Mulheres Trabalhadoras Rurais (vide a Marcha das Margaridas), a Rede de Educação do Semi-Árido Brasileiro (RESAB), Comissão Pastoral da Terra (CPT), além de uma série de organizações de âmbito local. (MUNARIM, 2008, p. 61).
A base da educação do campo ${ }^{3}$ é o Programa Nacional de Educação na Reforma Agrária (PRONERA), com sua participação nas políticas públicas voltadas para a população do campo. Foram conquistas dos movimentos sociais do campo que resultaram no desenvolvimento do PRONERA no espaço público, avançando na experiência e na luta por reivindicações acerca das demandas dos movimentos sociais nos planos de ação do Estado.

Tal busca teve como justificativa o caráter histórico da exclusão na educação nacional, que desde o seu princípio primou pela desigualdade e contemplou a elite na formação educacional, caracterizando-se desde cedo como a exclusão de uns e o privilégio de outros. São ainda visíveis as desigualdades na educação, com relação tanto ao acesso quanto à qualidade, em diferentes níveis de escolarização e com maior ênfase no ensino superior.

Os argumentos de lutas reivindicatórias e propositivas realizadas em prol da educação para todos, pelos movimentos sociais e pela sociedade civil, têm como prerrogativa a definição constitucional: educação como direito universal, de todos. Os cidadãos são iguais perante a lei, e todos são sujeitos de

${ }^{3}$ Os meados da década de 1990 constituem o momento histórico em que começou a nascer o que estou chamando de movimento de educação do campo no Brasil. Nesse contexto, o "I Encontro Nacional de Educadoras e Educadores da Reforma Agrária” (I ENERA), realizado em julho de 1997, na Universidade de Brasília, pode ser eleito como o fato que melhor simboliza esse acontecimento histórico. O "Manifesto das Educadoras e Educadores da Reforma Agrária ao Povo Brasileiro", lançado na ocasião do evento, podem ser considerado a certidão de nascimento desse acontecimento (MUNARIM, 2008, p. 59).

Para saber mais sobre os momentos historicamente produzidos que compõem a educação do campo, ver Munarim, A. Trajetória do movimento nacional de educação do campo no Brasil. Educação (UFSM), Brasil, 2008. 
direitos, independentemente das características que os especifiquem ou diferenciem. Todavia, tal preceito não condiz com a realidade brasileira, permeada pela existência de desigualdades. A validade constitucional só existe, em sua garantia, se o Estado construtor de tais direitos estiver presente sob a forma de políticas públicas, amplas e abrangentes, promovendo a superação das desigualdades e consentindo na participação da sociedade civil.

Entendemos como responsabilidade do Estado promover o acesso aos direitos dos indivíduos que compõem um determinado grupo social que tem mais dificuldades. Não basta que o Estado garanta apenas formalmente os direitos universais. Além de ter uma postura ativa na formalização de políticas públicas que estabeleçam direitos aos excluídos, ele deve ter um posicionamento intervencionista para poder desencadear políticas específicas para os grupos em situação desfavorável, criando condições para modificar o quadro vigente.

A evidência de que existe a condição dos excluídos no acesso ao ensino superior universitário e também de que compete ao Estado modificá-la de forma substancial e concreta tem sido o vetor da luta dos movimentos sociais que reivindicam a educação do campo sob os princípios de igualdade, valorização, respeito e identidade da população do campo.

Lembramos a importância da educação do campo como compromisso de reconhecimento dos moradores do campo como sujeitos de uma história e de uma identidade diferenciadas; sujeitos que têm como premissa de seus direitos a manutenção de sua singularidade, expressa na valorização do campo como espaço de vida, cultura e trabalho, exigindo que o acesso à educação favoreça a criação de alternativas para construir outro conhecimento e práticas emancipatórias (JESUS, 2004).

Nessa perspectiva, a educação do campo preconiza o desenvolvimento humano em todas as suas dimensões, o respeito aos saberes da experiência e à cultura dos sujeitos do campo, e entende o contexto e a realidade camponesa como base, como ponto de partida e de chegada de suas ações e reflexões.

Na concepção de educação sugerida pelo coletivo de movimentos sociais do campo prospera a teoria pedagógica, provocando a produção de conhecimentos apropriados e com capacidade de articular diferentes dimensões da vida dos sujeitos do campo no processo educacional.

Ao se trazer informações novas e históricas da população do campo para a universidade pública, ocorre uma mudança significativa no contexto científico, como um novo modelo de produção do conhecimento sobre procedimentos teórico-metodológicos que fomentam a construção emancipatória do sujeito.

Não é o caso de relegar a natureza individual das atividades da universidade, nem de que os professores sejam dispensados e alunos dos movimentos sociais tomem seus lugares; ao contrário, quando o assunto é propor um novo modelo de produção do conhecimento, pretende-se que os alunos e os professores se tornem parceiros em um processo formativo, aceitando o novo por parte de cada um dos envolvidos, de seus saberes e conhecimentos acumulados.

$\mathrm{O}$ ingresso dos movimentos sociais na universidade vai além dos limites da sala de aula, mas propõe-se que os alunos conheçam o cotidiano das universidades, em diferentes instâncias. Conforme adquirem aprendizado, obtido junto às instâncias, aos segmentos constituintes (docentes, discentes e 
corpo técnico administrativo), e conhecendo os protagonistas que os realizam, os alunos dos movimentos sociais do campo registram tais informações e as usam como base de reflexão crítica, compartilhando os seus conceitos com aqueles que acompanham a sua experiência.

Em razão do conhecimento dos movimentos sociais quanto aos investimentos no processo formativo de âmbito escolar e extraescolar, a contribuição dos movimentos sociais é relevante na criação de uma alternativa para as relações sociais que se cristalizaram na universidade.

A troca de conhecimentos e a maior participação dos movimentos sociais no contexto das universidades públicas podem reverter em ganhos reais para todos os envolvidos: universidades e sujeitos dos movimentos sociais.

A universidade pública, face aos novos conhecimentos trazidos pelos movimentos sociais, depara-se com a possibilidade de transformações na instituição e no papel do conhecimento científico, a exemplo da metodologia da alternância em cursos superiores universitários para os grupos populares do campo. Essa opção favorece a exploração do ingresso em uma cultura, a organização do trabalho e da política no relacionamento com a população do campo, privilegiando os saberes acumulados que foram sonegados, descaracterizados ao longo do tempo, como aponta a "sociologia das ausências" definida por Santos (2006).

Considerando a sociologia das ausências disposta por Santos (2006), verificamos que ocorre uma transformação dessas ausências em presenças, quando a universidade pública e os movimentos sociais realizam uma troca interativa da cultura e conhecimento da população do campo com o conhecimento científico e não científico. Quando novos saberes, oriundos de registros temporais e históricos, são aceitos em uma discussão que lida com conceitos modernos, apresentam-se conjuntamente as opções e oportunidades de que tais saberes se apresentem no cenário das disputas das políticas nacionais.

A defesa dos movimentos sociais pela implementação de políticas públicas específicas para o ensino superior universitário insere conceitos, como os de socialização, sociabilidade, cultura, campo e comunidade, associados de modo permanente com a educação específica do campo, e agora se alargando pela implementação de políticas públicas para essa educação.

No cenário institucional, cabe a inserção da universidade para todos, a exemplo do que indagou Chauí (2001, p.34) - “como inserir a universidade na sociedade?” - posto que é ela uma instituição social, mas que absorve e exprime as ideias e práticas neoliberais dominantes.

Segundo Dias Sobrinho (2005), inerente à democracia, evolui a globalização, e ainda que seja um fenômeno complexo e plurirreferencial, apresenta contradições inseridas em ideias divergentes, posturas e concepções, predominando julgamentos de que a universidade deve fomentar as transformações exigidas pela nova economia de mercado. Porém, ao aderir aos objetivos da sociedade, passa a universidade ao largo de sua função de formação, de educação e de autonomização dos sujeitos, aproximando-se da dinâmica da produção e de um pretendido controle das relações entre os indivíduos. Nesse caso, "Cabe à universidade [...] elaborar uma compreensão ampla e fundamentada relativamente às finalidades e transformações da sociedade" (DIAS SOBRINHO, 2005, p. 165).

Assim, a universidade não é apenas um local de transmissão de conhecimentos, 
mas de produção e sistematização. A perspectiva teórica da universidade e educação relaciona-se com a ideia de democratização das práticas sociais; e, nelas, das práticas educativas.

Quando se reflete sobre a universidade definida como local de produção e sistematização, é importante registrar a percepção definida por Augusto, Inácia e Ioná⿴囗, com respeito às expectativas pelo curso que realizam:

"No curso de Pedagogia é diferente, porque ele desafiou a gente ir falar lá na frente, trabalhar em grupos, discutir, debater, coordenar a turma, coordenar os núcleos de base exige que você faça, eu acho que o curso regular não proporciona isso para os jovens, e nos nossos cursos superiores tem essa organicidade diferente, são as equipes de trabalho, ou seja, cada equipe tem sua responsabilidade, tem as avaliações, tem que ir atrás, tem que ir em busca. Porque para nós funciona mais ou menos assim; se nós queremos uma sociedade diferente tem que começar por nós mesmos fazendo diferente do que está posto, não adianta você só querer e não agir. Primeiro precisamos mudar a gente mesmo se queremos mudanças na sociedade e daí tu vê que a turma tem compromisso. No curso de Pedagogia, para você ter uma ideia, se tem alguém com dificuldade a turma avisa para a coordenação $e$ daí todo mundo se organiza para auxiliar essa pessoa; os próprios graduandos conseguem enxergar isso e trazer para o debate e achar soluções coletivamente para ajudar a essa pessoa para não ficar para trás”. (AUGUSTO)

Em relação à participação social e política no interior da universidade, denota-se, nas entrelinhas da fala de Augusto, que ele tem compreensão da dimensão e importância de formação docente, no contexto da educação do campo. A expressão grifada no depoimento reforça essa argumentação:

\begin{abstract}
“[...] eu acho que o curso regular não proporciona isso para os jovens, e nos nossos cursos superiores tem essa organicidade diferente, são as equipes de trabalho, ou seja, cada equipe tem sua responsabilidade, tem as avaliações, tem que ir atrás, tem que ir em busca” (AUGUSTO).
\end{abstract}

Em outro depoimento, confirma-se a natureza curiosa e o interesse em buscar o próprio aprendizado:

\begin{abstract}
"Compreender as dimensões das políticas públicas educacionais oferecidas aos estudantes no seu processo de construção é condição essencial e passos iniciais para quem almeja os propósitos da educação superior universitária. A abertura para uma visão mais ampla acerca das metodologias, conteúdos e estratégias didáticas que a universidade detém significaria ultrapassar conceitos de uma política educacional que se mantém nos parâmetros ideológicos da hegemonia da educação.

Não chega a ser uma frustração, mas devido ao tempo a carga horária para algumas disciplinas é pouca. Não é a curiosidade pela curiosidade, mas a curiosidade da gente vai além do que o tempo pode proporcionar, e eu sou umas das mais tagarelas da sala e nós temos vontade de tirar as nossas dúvidas e de repente a gente tem que fazer os trabalhos que são indicados e o tempo não cobre e não permite toda essa desenvoltura que talvez fosse uma questão anual. Ensino Médio, 55 minutos de aula, talvez não faria muita diferença, não sei como seria o programa para se mudar isso”. (ISOLDA).
\end{abstract}

$\mathrm{Na}$ fala de Isolda evidencia-se uma apreensão, uma clara indicação de que o tempo disponibilizado para o aprendizado não dá conta da amplitude de assuntos e das temáticas trabalhadas nas diferentes disciplinas. O ideal, portanto, é que as bases de estudos sejam amplas para não se cair apenas 
na reprodução de visões de mundo que já são referidas como equivocadas ou antagônicas, minimizando questões como a igualdade na educação. O depoimento aponta para a questão do próprio formato de escola "moderna" hegemônica, a organização de seus tempos e seu currículo.

Quando há mudanças na educação, elas são efetivamente sentidas e relatadas, a exemplo da fala de Eduardo.

"O avanço foi incrível principalmente de dois meninos que terminaram o ensino médio no Acampamento junto com a minha filha vieram meio assustados para a Pedagogia, mas vieram e realmente se identificaram para ver o avanço na escrita deles na dinâmica deles lá na escola, da teoria e da prática depois com a volta com as crianças lá na escola de se colocar no processo, agora tomam a iniciativa, voltam para lá se pondo em roda, círculo....” (EDUARDO).

Os entrevistados têm certa clareza dos objetivos do curso e manifestaram compreensão de seu papel social e do retorno que devem oferecer à comunidade, durante e após a conclusão do curso, percebendo-se como agentes promotores de melhorias educacionais e de qualidade de vida na comunidade.

É possível ainda apreender, nas discussões dos entrevistados, o retrato do sentimento com relação às expectativas e às utopias do Movimento, especificamente com relação à formação dos seus integrantes para educadores do campo e para a luta mais ampla.

A educação do campo, nas universidades, vem confirmando que a universalização da educação e a formação de educadores do campo são possíveis com qualidade e acesso de todos aos níveis de ensino; portanto, com consequente aumento da escolaridade no meio rural.
Desde que os movimentos sociais do campo $^{4}$ incluíram em suas reivindicações a educação, parcerias foram firmadas com universidades, ONGs e Estado, com resultados verificados em princípios, matrizes conceituais e práticas. Nas políticas públicas, os resultados das lutas organizadas pelo MST são vistos em sua implantação, para garantir o cumprimento do direito de acesso universal à educação.

Diante da implementação das políticas públicas para a educação do campo, a universidade pública recebe uma temática nova, que se robustece como área de pesquisa, ensino e extensão.

O estabelecimento da educação do campo como um dos objetivos do MST vem direcionando novos avanços educacionais no que concerne à formação superior

${ }^{4}$ A década de 1990 registra a realização do primeiro curso formal de magistério ligado ao Movimento Sem Terra, no Estado do Rio Grande do Sul, visando atender à necessidade do Movimento na formação de educadores. O primeiro curso de Pedagogia da Terra tem sua gênese nesta iniciativa, que foi percebida como uma experiência pelo MST e a possibilidade de caracterização de um lugar de formação de militantes da educação no Movimento, e não limitado ao trabalho direto na escola (CALDART, 2002).

Em 1994 as discussões com o Setor de Educação do MST para organizar um curso superior de Pedagogia deram início às negociações para parcerias com as universidades. Em 1998 foi criada a primeira turma de Pedagogia da Terra, na Universidade Regional do Noroeste do Estado do Rio Grande do Sul - UNIJUí, com sede em Ijuí. Na continuação, o Movimento lutou pela criação de outros cursos superiores de Pedagogia da Terra no Brasil. No Paraná, em processo iniciado no ano de 1998, as primeiras negociações se realizam com a Universidade Federal do Paraná (UFPR), seguida da Universidade Estadual de Ponta Grossa (UEPG) e da Universidade Estadual de Maringá (UEM), sem sucesso em nenhuma das tentativas. No ano de 2001, as negociações com a Universidade Estadual do Oeste do Paraná (Unioeste) implicaram na reorganização do Projeto Político Pedagógico e, em 09 de dezembro de 2002, na sede da Unioeste em Cascavel, Paraná, é aprovada a proposta de criação do curso. 
universitária dos seus educadores, em cursos específicos ligados ao Movimento, como, por exemplo, o Curso de Pedagogia para Educadores do Campo na Unioeste, foco deste estudo, entre outros implantados em vários estados da Federação. Na Figura 1 são mostradas as universidades que oferecem a formação universitária para educadores do campo e suas respectivas localizações nas regiões e Estados brasileiros.

Figura 1 - Localização das universidades que oferecem cursos para a formação dos educadores do campo. Fonte: Brasil República.com, 2011.

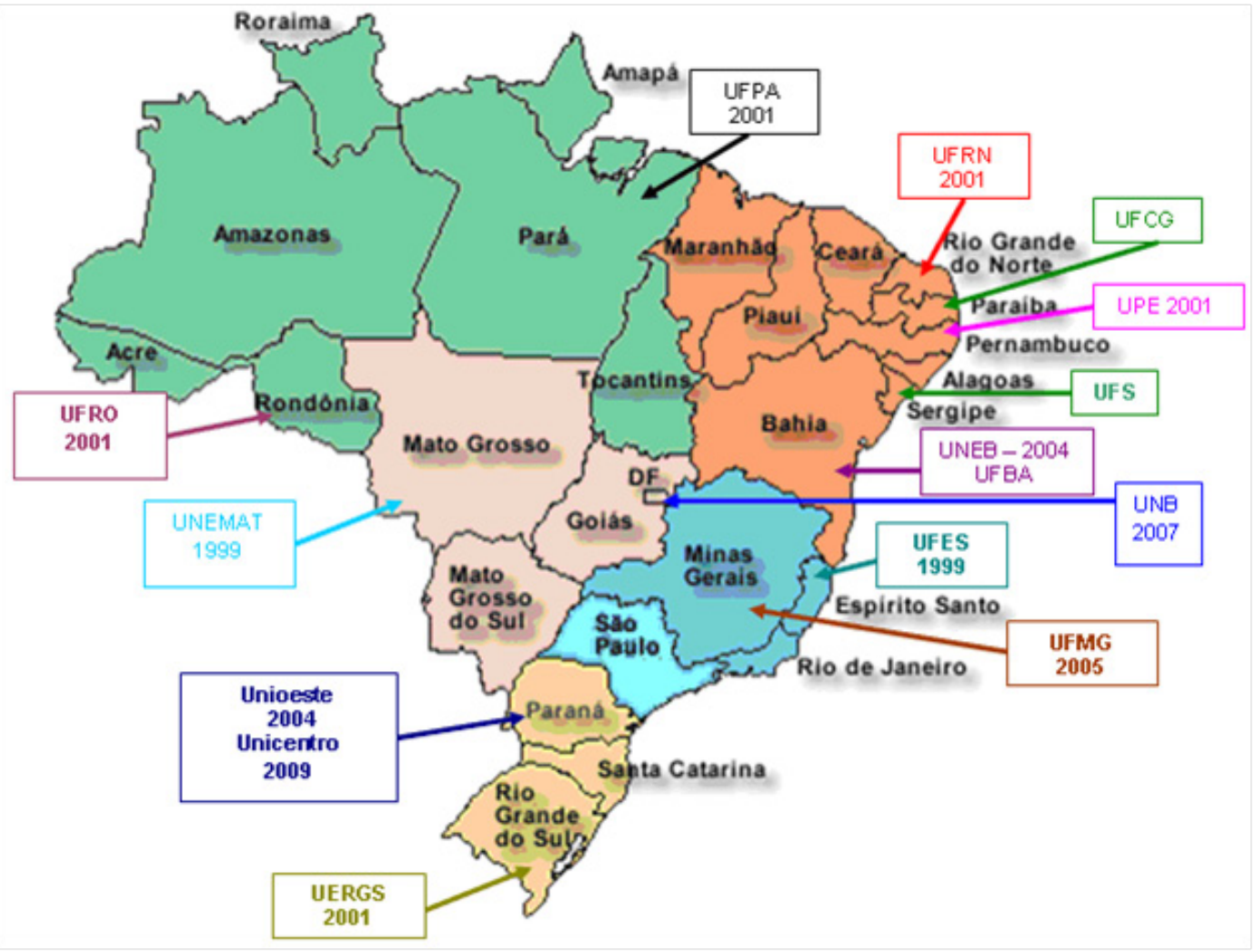

Os dados mostram que, atualmente, as instituições universitárias que oferecem Curso de Pedagogia para educadores do campo/Pedagogia da Terra para a educação do campo totalizam 13 universidades em 13 estados da federação. Observa-se, ainda, maior concentração nos estados do Nordeste brasileiro, com cinco instituições. Na região Sul, são três as instituições, em dois estados: Paraná, com a Unioeste e a Universidade Estadual do Centro Oeste - Unicentro; e Rio Grande do Sul, com a Universidade Federal do Rio Grande do Sul. No Sudeste brasileiro, são duas instituições de ensino superior para a educação do campo, em dois estados: Espírito Santo e Minas Gerais.

O Curso de Pedagogia para Educadores do Campo é resultado da luta travada pelos movimentos sociais do campo por educação. As necessidades desses movimentos em acessar o conhecimento historicamente sistematizado fizeram com que fossem à luta e reivindicassem o direito à educação para os sujeitos do campo. 
Exemplo dessa conquista é a efetivação do Curso de Pedagogia para Educadores do Campo na Unioeste, materializado pela necessidade do Movimento em resgatar os saberes e conhecimentos da população do campo e inseri-los no contexto da modernidade como uma reivindicação justa e de direito social.

A primeira turma de Pedagogia para Educadores do Campo teve início em julho de 2004, e a segunda em 2009, com o objetivo de formar educadores para as séries iniciais do Ensino Fundamental e formar pedagogos capazes de articular processos de formação nas famílias e comunidades do campo, na perspectiva de fortalecer os seus projetos de vida, articulados a um projeto de desenvolvimento.

Nesse sentido, a universidade é chamada à construção de uma parceria mais estreita com os movimentos sociais, objetivando a sua emancipação político-cultural. Para eles, há a expectativa de que as perspectivas filosóficas e científicas auxiliem na instrumentalização e construção de suas práticas, visando a compreendê-las melhor, na proposta de discutir, subsidiar ações que impulsionem o desenvolvimento, sobretudo o regional.

A universidade, enquanto instituição dedicada à produção de conhecimentos, tem o compromisso de estabelecer uma relação mais estreita com a sociedade, buscando refletir sobre a situação sócio-político-cultural do espaço geográfico em que se encontra inserida e, através de ações, colocar-se mais próxima da comunidade, para que esta participe de sua prática e ação social.

Os dados apresentados favorecem uma conclusão sobre as ações do MST, como princípio educativo que transforma os seus integrantes em sujeitos que buscam uma proposta da educação do campo espe- cífica para os trabalhadores sem terra. Nesse processo estão subjacentes propósitos de formação no ensino superior universitário voltado para o trabalho de base do movimento, visando a adquirir capacidade de articular as discussões com o Estado sobre as políticas educacionais desejadas para a população do campo.

Conforme Silva (2000, p.3), a universidade, voltada para as demandas da sociedade e levando em consideração os problemas desta, "reafirma, assim, seu compromisso social diante de questões que vêm exigir a redefinição de suas práticas de ensino, pesquisa e o atendimento aos apelos veiculados pelos referidos movimentos”.

Nas falas dos egressos Caio e Cristiano, é possível compreender a relação que os militantes, integrantes do MST, estabelecem com a universidade e, consequentemente, com o conhecimento historicamente sistematizado, que os movimentos sociais desenvolvem a luta para acessar.

"A universidade e assim no curso todo, as diversas disciplinas foram muito boas, então o conjunto de professores teve muito que nos ensinar, nós não tínhamos conhecimento, que tivemos acesso ali, e isso qualifica a nossa prática. Hoje a gente vai para a negociação com o governo $e$ nós discutimos currículo com o governo, aqui na Secretaria de Educação, entendemos de escola, entendemos de currículo, ensino, metodologia... Então, você qualifica, porque nós assim, o Movimento desde a sua teoria da educação, desde os seus aprofundamentos busca o acesso à universidade para qualificar isso, para qualificar o próprio projeto de educação do Movimento [...], claro que sabemos que temos de melhorar, temos de ir avançando. Mas, as disciplinas deram conta, boa carga e boas referencias para a gente poder hoje fazer avançar a luta” (CAIO). 
"Acho que uma das dificuldades até que a universidade conheça a proposta porque têm muitas coisas que são barradas, o nosso jeito de se organizar é diferente das outras e tem uma coisa de dizer que é muito puxado por ter essa organicidade, $a$ visão dos outros também eles olham e dizem vocês exigem demais, mas não é faz parte é um processo educativo, não que a sala de aula não seja, é com certeza, mas essa outra parte formativa ajuda crescer e compreender o próprio processo da sala de aula para que não se sinta sou diferente e por todo esse processo formativo vai entendendo todo o processo ai você entende que não somos diferentes. Somos em poucas partes diferentes da organicidade, mas não que [...]" (CRISTIANO).

São ações concretas que se realizam, conforme o MST se expande e forma os seus atores, que passam a representarem-se como instrumentos para mudanças amplas na educação do campo e determinam, aos poucos, a acomodação dessa nova proposta, conforme descreveu Cristiano: “[...] compreender o próprio processo da sala de aula para que não se sinta: sou diferente”.

A perspectiva de uma nova visão sobre o campo pode ser concretizada, se os profissionais da educação receberem uma formação cujo projeto de escola também apresente essa posição. Para que isso ocorra de modo efetivo, a formação docente deve ser contextualizada e presente no tempo e no espaço, destinada à redução das desigualdades educacionais que vigoraram até hoje.

Os avanços nas propostas educacionais dos cursos específicos para o MST, citados pelos egressos, correspondem, certamente, ao planejamento desse movimento que luta pelo acesso à formação universitária superior, pois confere ao militante capacidade de articular as discussões de que necessita para posicionar-se frente ao Estado e demandar uma política educacional específica.
Artur, entrevistado para este trabalho, entende que o acesso à universidade trouxe mudanças para si, como indivíduo e como sujeito em formação, possibilitando-lhe inferir na construção crítica do contexto de seu entorno:

\begin{abstract}
"A mudança, eu acredito que eu já tinha uma visão mais crítica do mundo que se tem hoje, mas, com o curso de Pedagogia, trouxe mais elementos para fazer as análises desse processo, oportunidade de estar fazendo novas leituras e aprofundar as velhas, digamos assim, para construir uma crítica mais fundamentada da vida, da sociedade e a inserção nos diversos espaços de discussões que, a partir da Pedagogia, foi possível” (ARTUR).
\end{abstract}

As ações do MST são confirmadas pelos depoimentos, com descrição de diferentes sentimentos com relação às expectativas do curso superior para os integrantes do MST.

Para os alunos da Pedagogia para Educadores do Campo sujeitos desta pesquisa um dos objetivos é adquirir conhecimentos que possibilitem a emancipação social e pessoal e socializar essa formação com o coletivo do MST. No entanto, a literatura e os dados empíricos mostraram que a busca do movimento pelos cursos superiores universitários, para a formação de educadores do campo, tem ligação direta com a formação e a manutenção do MST.

A reprodução do movimento é entendida como necessária quando são considerados os elementos da práxis da educação do campo, realizada na base do movimento e na formação de militantes, a fim de assegurar a sobrevivência de seus integrantes e a ampliação das lutas. Desse modo, o objetivo da formação universitária tem estreita vinculação com a obtenção de um conhecimento individual, por meio da formação, e de dis- 
seminação deste com a coletividade, a base de luta do MST.

Concluindo, entende-se que o acesso de integrantes do MST no ensino superior universitário tem trazido contribuições singulares a todo o complexo do movimento. Tem possibilitado aos seus membros uma formação que os instrumente para a discussão sobre a formatação das políticas educacionais com o Estado, a formação como sujeitos dotados de identidade e imbuídos nos propósitos coletivos. Mas, especialmente, tem se constituído em proposta nova de reivindicação para os direitos sociais.

\section{Considerações finais}

Na investigação, é evidente, para os militantes integrantes do MST, a necessidade de formação superior universitária como instrumento fundamental para a melhoria das condições de sobrevivência nos acampamentos e assentamentos. Além disso, essa formação possibilita a capacidade de gerir as suas próprias vidas. Ou seja, os militantes têm clareza sobre o que a educação/formação poderá auxiliá-los também na formatação da luta pela conquista de seus objetivos mais amplos.

Compreende-se, neste estudo, que as necessidades e os interesses da população do campo exigem debruçar-se sobre uma estratégia política diferenciada, com um olhar voltado a um modelo de desenvolvimento que agregue sustentabilidade e qualidade. Assim, considera-se imprescindível que as famílias continuem suas atividades nas áreas rurais, que lhes sejam possibilitadas novas formas de produção e de sobrevivência.

Entende-se que, dentre as estratégias do MST, encontra-se uma das mais importantes: a ampliação do conhecimento coletivo por meio da educação. Com isso, o MST pretende fortalecer-se como movimento social, e assim também a base dos Sem Terra. Ao lutar pela formação superior universitária de seus militantes, o MST fundamenta as suas estratégias de atuação, porque as mudanças de visão e atitudes dos graduandos/egressos passam a justificar ações como ator propositivo de novas experiências em novos e velhos ambientes.

Não está finalizada, porém, a luta pela educação do campo, se analisada a concessão feita pelas políticas públicas educacionais para a qualidade nessa forma de educação a partir dos cursos de Pedagogia para Educadores do Campo. O que se tem claro é o imenso caminho que se abre para que a população do campo acesse o ensino superior universitário rumo à universalização da educação.

\section{Referências}

CHAUÍ, M. Escritos sobre a universidade. São Paulo: Editora UNESP, 2001.

DIAS SOBRINHO, J. Educação superior, globalização e democratização: qual universidade? Revista Brasileira de Educação, n.28, p.164-73, 2005.

GOHN, M. G. O protagonismo da sociedade civil: movimentos sociais, ONGs e redes solidárias. 2. ed. São Paulo: Cortez, 2008a.

Teoria dos movimentos sociais: paradigmas clássicos e contemporâneos. 10 ed. São Paulo: Edições Loyola, 2012.

Movimentos sociais e educação. 8. ed. São Paulo: Cortez, 2012.

JESUS, S. M. A. Questões paradigmáticas da construção de um projeto político de educação do campo. In: MOLINA, M. C.; JESUS, S. M. S. A. (Orgs.). Contribuições para a construção de um projeto de educação do 
campo. Brasília: Articulação Nacional Por uma Educação do Campo, 2004.

MST. Lutas e conquistas, reforma agrária: por justiça social e soberania popular. São Paulo: Secretaria Nacional do MST, 2010.

MUNARIM, A. Trajetória do movimento nacional de educação do campo no Brasil. Educação, UFSM, v.33, n.1, 2008.

SADER, E. Quando novos personagens entraram em cena: experiências, falas e lutas dos trabalhadores da Grande São Paulo (1970-80). Rio de Janeiro: Paz e Terra, 2001.

SANTOS, B. S. A gramática do tempo: para uma nova cultura política. São Paulo: Cortez, 2006.

STÉDILE, J. P.; FERNANDES, B. M. Brava gente: a trajetória do MST e a luta pela terra no Brasil. 3. ed. São Paulo: Fundação Perseu Abramo, 2005.

SILVA, R. C. C. Os sem-terra e o desejo de aprender. 2000. 181f. Dissertação (Mestrado em Educação). João Pessoa: Universidade Federal da Paraíba, 2000.

VALENÇA, M. M. O movimento dos trabalhadores rurais sem terra (MST) e a universidade pública brasileira: um caso de tradução. Revista de Ciência, Tecnologia e Humanidades do IFPE, Ano 1, n.1, p.78-90, 2009.

Recebido em 10/3/2012

Aprovado em 27/3/2012 